\title{
Le Crime de la rue Chanoinesse de Albert Bizouard: análisis, versión y estudio traductológico
}

\author{
(Albert Bizouard's Le Crime de la rue Chanoinesse: \\ analysis, version and translation study)
}

Carmen Arnedo Villaescusa marnedo@cordoba.uned.es

UNED

Fecha de recepción:12 de enero de 2015

Fecha de aceptación: 16 de febrero de 2015

Resumen: Trabajo que trata de uno de los novelistas que sigue la estela del iniciador del relato policíaco en Francia: Émile Gaboriau, y que como su predecesor sigue todos los procedimientos inherentes a él: un lenguaje enfático y exagerado, propios de los "romans-feuilletons" muy del gusto de la época y de las exigencias de los lectores de novela popular, así como su habilidad, a lo largo de la narración, para hacer progresar al lector. Bizouard lleva a cabo un tipo de análisis basado en una encuesta judicial más que en una investigación detectivesca. El trabajo compara el original con la traducción a través de los planos morfosintáctico, léxico-semántico y pragmático-cultural, que ponen de relieve los diferentes códigos lingüísticos utilizados en las dos lenguas.

Palabras clave: Bizouard, Novela policíaca, Traducción, Análisis traductológico.

Abstract: This paper examines Albert Bizouard, one of the novelists who follows in the footsteps of the pioneer of crime stories in France, Émile Gaboriau. Bizouard, like his predecessor, follows all the inherent processes of the genre: emphatic and overstated language characteristic of the romans-feuilletons, much in the taste of the era and catering to the demands of the readers of popular novels. This paper also examines Bizouard's ability throughout the story to make the reader advance. Bizouard's story is based more on a judicial enquiry than a detective investigation. This paper comparatively analyzes the original text in French to the translation in Spanish, by examining morphosyntactic, lexical-semantical, and cultural and pragmatic aspects of the work, which highlight the different linguistic codes used in the two languages. 
Key words: Bizouard, Roman policier, Translatology, Translation analysis.

\section{INTRODUCCIÓN: METODOLOGÍA DEL ANÁLISIS TRADUCTOLÓGICO}

Dado que el presente trabajo se centra en el análisis traductológico y comparativo de una obra literaria y su traducción, y teniendo en cuenta las características y objetivos que se persiguen, la metodología seguida para abordar este estudio se basa en un enfoque comparativo-descriptivo, tanto a nivel macrotextual como microtextual, detallando las principales técnicas de traducción empleadas para llegar al texto meta, así como las características reseñables que considero pertinente destacar con respecto a la traducción.

A pesar de las diferencias que se puedan hallar entre los dos códigos lingüísticos implicados en una traducción, la transferencia del contenido semántico se convierte en una necesidad de obligado cumplimiento, por lo que en muchas ocasiones, el traductor debe recurrir a múltiples técnicas de traducción para lograr dicho objetivo. Una de las más habituales es la equivalencia dinámica ${ }^{1}$ o funcional, mediante la cual se intenta comunicar la idea expresada en el texto base, si es necesario en menoscabo de la literalidad, del orden original de las palabras, de la voz gramatical del texto base, etc. No obstante, en la traducción literaria nos enfrentamos con textos en los que predominan los procedimientos artístico-literarios, y ante un lenguaje que no está hecho de unidades invariantes (clichés, dichos, registros lingüísticos predeterminados...), sino que es connotativo, plurisignificativo, en el que predomina la función poética o estética y que presenta una clara desviación del lenguaje normal. Estos condicionantes determinan que el traductor tenga que decidir no solo las técnicas que le van a permitir recrear segmentos concretos de traducción, sino ante todo, el método o métodos de traducción. Decimos "métodos", porque consideramos que a cada función textual se le puede aplicar uno o más métodos de traducción y que, en general, todas las traducciones comparten en cierto sentido el método comunicativo y el semántico, lo que varía es el énfasis puesto sobre uno u otro aspecto. Sin embargo, con este estudio determinaremos que las características particulares de los textos literarios suelen imponer el uso del método de traducción semántica, en el que el énfasis se ejerce sobre la lengua de salida, para que se rinda el exacto significado contextual del original. Por ello es muy común encontrarnos con traducciones oblicuas ${ }^{2}$, en las que se reiteran procedimientos de traducción ${ }^{3}$

\footnotetext{
${ }_{2}^{1}$ Expuesta por Eugène Nida.

${ }^{2}$ La estilística comparada sustituye la oposición literal/ libre por la literal/oblicua. O lo que es lo mismo, se opone la "correspondencia formal" de estructura y contenido (el grado cero) por la "correspondencia de contenido" que no implica necesariamente ni la correspondencia formal ni
} 
como el préstamo lingüístico, calco, traducción literal, transposición, modulación, equivalencia y adaptación.

A través del análisis de las traducciones que presentamos en este trabajo pretendemos entender el proceso y la lectura que del original hace el traductor de esta versión en un marco comunicativo espacio-temporal diferente. Dado que no me baso en una traducción (al no existir ninguna), he debido traducir el texto original; así pues, el análisis habrá de basarse en una metodología comparativo-descriptiva que permita establecer las posibles desviaciones de la traducción con respecto al original, para lo cual lo focalizaremos en los procedimientos de traducción oblicua siguiendo la taxonomía de Amparo Hurtado Albir (2011: 268-271).

Antes de proceder al análisis comparativo del texto original en francés y su traducción al español, dedicaré un breve apartado a esbozar los rasgos discursivos y lingüísticos del texto original.

En lo que concierne al análisis traductológico, se realiza teniendo en cuenta el nivel formal, morfosintáctico, léxico-semántico y pragmáticocultural y recogiendo las principales semejanzas o diferencias que se encuentren entre original y traducción. Para ello, se señalarán las principales técnicas de traducción empleadas, siguiendo como hemos anticipado la clasificación propuesta por Hurtado Albir, tales como la adaptación, ampliación lingüística, amplificación, calco, compensación, compresión lingüística, creación discursiva, descripción, equivalente acuñado, generalización, modulación, particularización, préstamo, reducción, sustitución, traducción literal, transposición, variación. Para desarrollar el análisis comparativo de las técnicas de traducción empleadas, iré seleccionando para su análisis, los segmentos del texto original más característicos o representativos y que evidencien cambios significativos en el texto meta.

\section{ANÁLISIS TRADUCTOLÓGICO DE LE CRIME DE LA RUE CHANOINESSE}

Albert Bizouard (1843-19...?), autor de la obra que trato, es un escritor del que no se cuenta con datos biográficos, a pesar de que buena parte de sus obras estén en la BNF (Gallica). Se sabe que nació en París y que fue durante años "chef de bureau honoraire de la préfecture de police", de ahí el título de otra de sus obras: Vingtans de police: souvenirs et anecdotes d'un ancien officier de paix (Paris: E. Dentu, 1881).

Por lo que concierne a la novela, Le crime de la rue Chanoinesse se publica primero en forma de "roman-feuilleton", género que conoce su gran

estructural, aquí es donde intervienen los métodos oblicuos que permiten reemplazar unidades y estructuras por otras de diferente clase.

${ }^{3}$ Jean-Paul Vinay y Jean Darbelnet definen y analizan estos siete procedimientos de traducción en Stylistique comparée du français et de l'anglais, Paris: Didier, 1958. 
esplendor por la gran difusión de los periódicos en esta época, y luego será editada como libro, en 1893, por las ediciones Calmann Levy ${ }^{4}$, París.

La novela es un verdadero viaje en el tiempo al París auténtico de La "Belle Époque", de la segunda mitad del siglo XIX. Este tipo de narraciones se diferenciaban de la literatura anterior en que sus protagonistas principales no pertenecían a las clases altas sino a las clases populares. De este modo, el autor conseguía que el pueblo se identificara aún más con los personajes de la novela y su problemática. En ella encontramos la descripción del ambiente de los obreros y las clases más desfavorecidas, las costumbres de la alta burguesía parisina, que lleva una dilapidada vida de lujo y de apariencias, los inicios de la policía, la Morgue, en fin, la descripción y la crítica de las distintas clases sociales que coexisten en la época.

Bizouard nos sumerge en el mundo de la instrucción judicial. A través de la denuncia de una desaparición, que luego se convertirá en asesinato, se van sucediendo informes judiciales, describiendo la actividad de los agentes, fiscales, forenses, jueces y trasladando en la novela las fórmulas y el tipo de redacción propios de las actas judiciales ${ }^{5}$.

En cuanto a la acción, está situada en 1869 , dando la fecha concreta del 16 de junio, en el viejo París, y precisa su localización en la calle Chanoinesse, nombre que da título a la obra, situada en pleno corazón de París, en la île de la Cité, junto a la catedral de Notre-Dame y del HôtelDieu. La localización del caso en un inmueble desvencijado y umbrío del barrio de Notre-Dame, donde se hacinan obreros y desempleados que se buscan la vida como pueden, nos lleva, a través de los interrogatorios del comisario a los inquilinos, a una descripción de las costumbres y el modo de vida de las clases sociales menos favorecidas en una época en la que el paro y la pobreza se cebaba en las personas de baja condición social. Y lo contrapone a un mundo de lujo y diversión, con la descripción de los paseos en calesas de la alta burguesía parisina, que pretende imitar a la nobleza, haciendo gala en todo momento de elegantes y ostentosos ropajes, asistiendo a espectáculos y a los restaurantes de moda más caros y lujosos.

\footnotetext{
${ }^{4}$ Más tarde será publicada por entregas por el periódico Suizo del cantón de Valais, Le Confédéré. Y gracias a los archivos de la biblioteca cantonal, en Sion, hemos podido acceder a la publicación íntegra de la obra, pues conserva en sus archivos las ediciones del periódico en las fechas que se publicó, comenzando la primera entrega el 11 de marzo de 1905 y la última el 16 de septiembre del mismo año, en 55 entregas, a razón de dos ediciones semanales, miércoles y sábados.

${ }^{5}$ El propio autor inicia su relato diciendo que va a trasladar los documentos del proceso en su forma administrativa: «Nous ne pouvons mieux faire que de placer sous les yeux du lecteur les diverses pièces dont se composait cette procédure. Quoiqu'elle soit un peu monotone, nous respecterons la forme administrative dans laquelle elles étaient rédigées».
} 
El viejo París está representado aquí al completo, en los diferentes barrios, en las calles, en las casas y en la gente que las habita.

La novela está dividida en cinco partes, publicadas en cincuenta y cinco entregas: "Prologue", "Double disparition", "L'instruction judicière", "Le testament" y "L'assassin"; dada la extensión de la obra hemos limitado el estudio traductológico al prólogo, en el que ya se ponen de relieve todas las claves para la comprensión del texto por parte del lector. Como he explicado en la introducción al trabajo, para llevar a cabo el análisis traductológico hemos procedido a un estudio contrastivo de los textos en lengua origen (en adelante TO) y el texto en lengua meta (en adelante TM) y, en los ejemplos seleccionados, hemos señalado en cursiva los vocablos, expresiones o estructuras sintácticas de cuyo análisis nos ocupamos, con objeto de facilitar su identificación ${ }^{6}$.

\subsection{Plano formal}

Como hemos dicho, la novela se estructura en cinco partes, y toda la historia tiene un hilo argumental que proporciona cohesión al texto. El estilo, buscando agradar al público, deseoso de sucesos, de historias de asesinatos y ambiente policial, transmite los formulismos y el estilo judiciales en muchos de sus episodios, intercalando las intervenciones de los protagonistas, donde abundan las frases cortas y las oraciones simples, coordinadas o yuxtapuestas, con las descripciones de los personajes y del ambiente social:

TO: «Mon père est de petite taille, il est âgé de 52 ans, assez fort et vigoureux, ses yeux sont bleus. II porte des favoris qui, comme ses cheveux, sont blancs.

TM: - Mi padre es bajo, tiene 52 años, bastante fuerte y robusto, de ojos azules. Lleva patillas que, como su pelo, son blancas.

TO: Lecture faite, la demoiselle François a persisté et signé avec nous. TM: Hecha la lectura, la señorita François ratificó y firmó su declaración

El uso de mayúsculas y minúsculas varía en las dos lenguas, pues tras los signos de interrogación y exclamación, en el texto francés, las palabras aparecen en minúscula y, a la inversa, las ponemos en mayúscula en español:

6 Como texto de base hemos utilizado la publicación en el periódico Le Confédérée. FEUILLETON DU CONFÉDÉRÉ, LE CRIME DE LA RUE CHANOINESSE PAR ALBERT BIZOUARD. Reproduction autorisée aux journaux ayant un traité avec M. Calmann-Lévy, éditeur, à Paris. 
TO: —Oh! non, monsieur, car, lorsque je lui ai monté sa dernière lettre.

TM: —iOh! No, señor, pues, cuando le subí la última carta.

TO: -Oh! mon Dieu, chère enfant, comment avez-vous appris ?...

TM: —¡Oh! Dios mío, querida niña. ¿Cómo se ha enterado...?

TO: Toutes ses facultés étaient concentrées dans cette pensée ardente, unique: qu'est devenu mon père?

TM: Todas sus facultades estaban centradas en esa única e hiriente idea: ¿Qué le ha pasado a mi padre?

Asimismo, difiere este uso en los gentilicios, que aparecen en mayúscula en francés y que he trasladado en minúscula en español:

TO: C'était une véritable grande dame et une véritable Parisienne.

TM: Era una verdadera gran señora y una verdadera parisina.

TO: le sieur Mérignac, vigoureux Limousin...

TM: el señor Mérignac, un limusino fuertote...

También difiere el uso de las comillas, ya que para introducir el discurso directo tras los dos puntos, aparece entre comillas en francés y debemos poner tras guión en español:

TO: «Ce matin, vers sept heures, je me rendis à nouveau rue Chanoinesse.

TM: -Esta mañana, hacia las siete, me fui de nuevo a la calle Chanoinesse.

\subsection{Plano morfosintáctico}

Es de señalar, en cuanto a las estructuras sintácticas, que en la obra domina el uso de oraciones simples, coordinadas y yuxtapuestas, sin duda para dar viveza al relato y trasladar al lector el registro de lengua oral.

TO: -Avez-vous remis récemment des lettres au sieur François?

-Oui, monsieur, je lui en ai monté plusieurs il y a peu de temps.

—N'était-ce pas vers les 29 mai, 4 et 11 juin 1869?

- Je ne saurais préciser les dates.

—Ainsi, vous avez remis ces lettres à M. François lui-même?

TM: - ¿Ha entregado usted recientemente alguna carta al señor François?

- Sí, señor, le subí varias hace poco tiempo.

- ¿No fue sobre el 29 de mayo, 4 y 11 de junio de 1869 ?

- No sabría decirle exactamente. 
— ¿Entonces, le dio las cartas al señor François en persona?

Encontramos numerosos formulismos y estructuras propias del lenguaje jurídico y administrativo:

TO: «Je viens, en conséquence, vous faire la susdite déclaration aux fins de droit.»

TO: - Vengo, por consecuente, a hacer la presente declaración a los efectos legales oportunos.

TO: Lecture faite, la demoiselle François a persisté et signé avec nous.

TO: Hecha la lectura, la señorita François ratificó y firmó su declaración.

El uso de diferentes procedimientos traductológicos, como la alteración total de la estructura sintáctica del texto, es necesario a veces:

TO: Elle ne pouvait croire à la disparition de son père.

TM: No podía creer que su padre hubiese desaparecido.

TO: -Faites-nous connaître les particularités que vous pouvez posséder sur la disparition du sieur François?

TM: -Díganos lo que sepa sobre la desaparición del señor François.

TO: j'ignorais même absolument qu'il eût un enfant.

TM: ni siquiera sabía que tuviera una hija.

TO: j'ai tout lieu d'attribuer sa disparition à un malheur.

TM: me temo que su desaparición se deba a una desgracia.

En otras es necesario utilizar el procedimiento traductológico de la omisión, alterando la estructura del texto origen para hacerla más propia a la lengua de llegada:

TO: Nous remarquons, en outre, qu'aucune de ces lettres adressées au sieur François n'a été décachetée

TM: Observamos, además, que ninguna de estas cartas ha sido abierta

TO: dont la clef avait été déposée la veille entre nos mains par la susdite demoiselle François.

TM: cuya llave nos había sido remitida la víspera por la mencionada señorita François.

TO: l'inventaire des objets trouvés dans la pièce où nous sommes...

TM: el inventario de los objetos encontrados en esta habitación... 
TO: Nous représentons à la femme Masouillet les trois lettres annexées à notre procès-verbal $\mathrm{n}^{\circ} 2$. Elle déclare les reconnaître comme étant celles qui lui ont été remises par le facteur.

TM: Le presentamos las tres cartas anexas al acta $n^{\circ}-2$. Las identifica como las mismas que le había entregado el cartero.

TO: la demoiselle François reconnaît parfaitement comme ayant été écrites de sa main et expédiées par elle.

TM: la señorita François identifica perfectamente como habiendo sido escritas y expedidas por ella.

Son frecuentes los casos en que cambiamos los adjetivos posesivos, cuyo uso es muy frecuente en francés, ante las prendas de vestir particularmente, por artículos determinados:

TO: son chapeau et ses souliers sont restés dans sa chambre.

TM: los zapatos y el sombrero están en su dormitorio.

TO: pour pourvoir à leurs besoins communs.

TM: para atender a las necesidades familiares.

He trasladado frases completas por oraciones nominales, alterando a veces la estructura sintáctica, modificando oraciones coordinadas por yuxtapuestas:

TO: ses grands yeux bleus avaient une douceur infinie et semblaient chercher à lire sur la figure d'Andrée.

TM: sus grandes ojos azules, de una dulzura infinita, parecían querer leer en el rostro de Andrée.

TO: elle était toute tremblante, tout émue, et pressait vivement la main de son amie.

TM: temblorosa, completamente conmovida, apretaba con fuerza la mano de su amiga.

TO: était un brave et digne homme, très poli, mais il était on ne peut moins communicatif.

TM: era un buen hombre, honesto, muy educado, pero menos comunicativo imposible.

A veces, la traducción del texto es prácticamente imposible, optando por cambiar la expresión completamente por otra equivalente en español:

TO: machine à faire du travail, se levant et se couchant avec le soleil. 
TM: un trabajador nato, que se levantaba y se acostaba con el sol.

En los siguientes casos se traduce la frase pasiva en el texto francés por una frase activa en español:

TO: Elle déclare les reconnaître comme étant celles qui lui ont été remises par le facteur.

TM: Las identifica como las mismas que le había entregado el cartero.

TO: ces faits n'impliquent que la disparition de votre père soit due, comme vous le supposez, à un malheur.

TM: esos hechos no implican que la desaparición de su padre se deba, como usted supone, a una desgracia.

TO: elle ne pouvait croire que celui dont elle était adorée...

TM: no podía creer que aquél que la adoraba...

En la siguiente frase, que paso de pasiva a activa, se cambia además el pretérito imperfecto de indicativo por un condicional simple:

TO: elle se heurtait sans cesse contre des difficultés qui ne devaient, hélas! être vaincues que bien longtemps après.

TM: se topaba sin cesar con dificultades que, desgraciadamente, no serían resueltas hasta mucho tiempo después.

Son frecuentes los casos de alteración de los sintagmas verbales de las frases, de TO a TM como, entre otros, el siguiente ejemplo, donde además cambiamos la estructura negativa por otra afirmativa:

TO: mais petit à petit on ne prêta plus attention à sa manière de vivre. TM: pero poco a poco fueron dejando de prestar atención a su manera de vivir.

Cambios de pretérito perfecto compuesto a presente de indicativo:

TO: —Hélas, madame, je n'ai rien appris encore.

TM: -Por desgracia, señora, no sé nada todavía.

TO: De tout quoi, nous avons dressé le présent procès-verbal.

TM: De todo lo cual, levantamos la presente acta.

Asimismo, ha sido necesario realizar cambios de pretérito pluscuamperfecto de subjuntivo a pretérito imperfecto de subjuntivo:

TO: comme si l'infortuné vieillard eût pu entendre son appel. 
TM: como si el infortunado viejo pudiera oír su llamada.

Y también cambios de presente de indicativo por pretérito perfecto simple:

TO: Depuis ce jour, je n'ai pas rencontré M. François, et ce n'est qu'avanthier.

TM: Desde ese día, no me he cruzado con el señor François, y no fue hasta anteayer.

Cambios de presente de indicativo a presente o pretérito imperfecto de subjuntivo:

TO: je réponds aux personnes qui peuvent avoir affaire aux locataires de la maison.

TM: yo contesto a las personas que puedan querer algo con los inquilinos de la casa.

TO: On voit que la vie en est absente; elle a l'aspect d'une nécropole déserte.

TM: Se ve como si faltara la vida; parece una necrópolis desierta.

TO: Si le lecteur veut bien pousser avec nous cette porte.

TM: Si el lector quisiera empujar con nosotros esa puerta.

En alguna ocasión he sustituido unos verbos por otros, manteniendo el tiempo verbal:

TO: que ce dernier avait été obligé de travailler depuis des années comme ouvrier et comme contre-maître.

TM: este último se había visto obligado a trabajar desde hacía años de obrero y de contramaestre.

TO: je rentre souvent assez tard, dans l'obligation où je suis de prendre mes repas au dehors.

TM: vuelvo a menudo bastante tarde, pues me veo obligado a comer fuera.

Cambios de pretérito anterior a pretérito perfecto simple:

TO: Lorsqu'elle eut fini...

TM: Cuando acabó...

Cambios de pretérito imperfecto a pretérito perfecto simple: 
TO: La dernière fois que je l'ai vu, c'était il y a environ quinze jours

TM: La última vez que lo vi, fue hace unos quince días

TO: - N'était-ce pas vers les 29 mai, 4 et 11 juin 1869 ?

TM: - ¿No fue sobre el 29 de mayo, 4 y 11 de junio de $1869 ?$

Por otro lado, son de destacar, por su elevada frecuencia, los cambios de participio de presente por oraciones de relativo:

TO: se trouvait un nouveau procès-verbal débutant en la forme ordinaire et continuant en ces termes.

TM: se encontraba una nueva acta que empezaba en la forma ordinaria y que continuaba en estos términos.

TO: s'engager dans l'allée humide donnant accès à l'escalier.

TM: meterse en el húmedo pasillo que da acceso a la escalera.

TO: la seconde pièce, servant de chambre à coucher au sieur François.

TM: la segunda habitación, que sirve de dormitorio al señor François.

En otros casos optamos por traducir el participio de presente por oraciones subordinadas causales:

TO: Sortant tous les jours de bon matin pour aller à mon ouvrage, je rentre souvent assez tard.

TM: - Como salgo todos los días temprano para ir a mi trabajo, vuelvo a menudo bastante tarde.

TO: Etant presque toujours absent de chez moi...

TM: -Como casi siempre estoy ausente...

Otras veces, se sustituye el participio de pasado por estructuras preposicionales:

TO: Ce titre au porteur, numéroté 215,342 , est mis sous scellé par $M$. le juge de paix.

TM: Este título al portador, con número 215.342, es puesto bajo precinto por el señor juez de paz.

Cabe señalar el caso frecuente de la estructura francesa de "gérondif" que, en español, trasladamos por estructuras de "al+ infinitivo" como en los casos siguientes:

TO: En prononçant ces derniers mots, Andrée se mit à sangloter 
TM: Al pronunciar estas últimas palabras, Andrée rompió en sollozos

TO: En entrant, nous constatons que le plus grand ordre règne dans la pièce où nous nous trouvons

TM: Al entrar, constatamos que un gran orden general reina en la habitación donde nos encontramos

TO: En la voyant, on se sent envahi par une tristesse indéfinissable

TM: Al verla, uno se siente presa de una tristeza indefinible

TO: en mourant, ne lui avait laissé pour toutes ressources qu'une maigre pension de cinq cents francs.

TM: al morir, le había dejado como únicos recursos una flaca pensión de quinientos francos.

Asimismo, son frecuentes los casos en que se traduce la estructura "après+infinitivo compuesto", que obliga en francés a utilizar el tiempo compuesto, pero en español resulta una estructura muy densa, así pues, la he vertido por "después+ de+ infinitivo simple", o la he evitado con un sintagma preposicional, como en el último ejemplo:

TO: et je suis redescendue après avoir sonné pour l'avertir.

TM: y bajé después de llamar al timbre para avisarlo.

TO: Après avoir assisté aux constatations judiciaires...

TM: Después de asistir a las verificaciones judiciales...

TO: Madame de Meyrins, après avoir respecté quelque temps le silence d'Andrée.

TM: La señora de Meyrins, tras respetar un tiempo el silencio de Andrée.

TO: Après avoir terminé l'inventaire, $\mathrm{M}$. le juge de paix procède...

TM: - Tras el inventario, el señor juez de paz procede...

Por otra parte, debemos señalar también el caso del pronombre adverbial "en", inexistente en español, cuya ausencia se suple con el uso del posesivo "su" en LM:

TO: François déclare qu'elle en ignorait absolument l'existence...

TM: François declara que ella ignoraba totalmente su existencia...

TO: sa destinataire ne peut en comprendre le sens.

TM: la destinataria no puede comprender su significado. 
TO: la clarté semblait en rehausser encore la blancheur.

TM: la claridad parecía realzar aún más su blancura.

Cambios de estructuras de "faire+infinitivo" que traduzco por un verbo simple en español:

TO: la demoiselle François nous fait remarquer une cage.

TM: la señorita François nos señala una jaula.

TO: -Oh! non, monsieur, je les ai fait passer, comme j'en avais I'habitude, sous la porte du logement.

TM: — ¡Oh! No, señor, se las pasé, como acostumbraba, por debajo de la puerta.

TO: et surtout sans lui en faire connaître les motifs.

TM: y, sobre todo, sin darle a conocer los motivos.

Sustituciones de unos vocablos por otros, como en el ejemplo siguiente en que se altera la oración de relativo, se sustituye el posesivo por artículo determinado y se pasa de plural "dates" al singular "fecha":

TO: les timbres dont elles sont revêtues indiquent leurs dates de départ...

TM: los sellos que portan indican la fecha de expedición...

Me he visto obligada a realizar cambios de participios en francés por oraciones de relativo en español y viceversa, como en las siguientes frases, donde se dan ambos casos, siempre con el objetivo de hacer la traducción lo más cercana posible al receptor:

TO: nous remet trois lettres trouvées par elle sur la petite table dont nous venons de parler plus haut.

TM: nos remite tres cartas que encontró en la mesita arriba mencionada.

TO: une cage qui se trouve accrochée en dehors de la fenêtre.

TM: una jaula enganchada por fuera de la ventana.

TO: le soleil lança ses derniers rayons, qui éclairèrent le groupe émouvant formé par ces trois femmes.

TM: el sol lanzó sus últimos rayos, iluminando al emotivo grupo formado por las tres mujeres.

Cambios de sintagmas preposicionales por adjetivos o por adverbios: 
TO: Toujours rasé de frais, soigné dans sa modeste tenue...

TM: Siempre recién afeitado, cuidado en su modesto atuendo..

TO: sur l'enveloppe duquel on lit, écrit en haut...

TM: en cuyo sobre se lee, escrito arriba...

TO: fait qui prouverait que les oiseaux ont reçu des soins récents.

TM: hecho que probaría que los pájaros han recibido cuidados recientemente.

TO: -Depuis quinze ans, et il n'y en a guère que six que $M$. François a emménagé chez nous.

TM: - Desde hace quince años, y hace apenas seis que el señor

François se mudó aquí.

TO: Comme je ne sors que très rarement...

TM: Como rara vez salgo...

Cambios de estructuras verbales más complejas en francés, como "avoir connaissance de quelque chose", son sustituidas por un verbo simple en español "saber algo":

TO: s'il eût possédé cette somme elle en aurait eu certainement connaissance.

TM: si hubiera poseído esta suma, sin duda, ella lo habría sabido.

Ha sido necesario hacer cambios en el número y la persona de las formas verbales $y$, por ende, en los pronombres personales:

TO: Ladite demoiselle nous dépose une photographie de son père, que nous transmettons ci-joint.

TM: La mencionada señorita deja una fotografía de su padre, que se incluye aquí adjunta.

\subsection{Plano léxico-semántico}

Dentro del campo léxico es de señalar la gran cantidad de términos pertenecientes al lenguaje jurídico que domina en toda la obra:

TO: une volumineuse procédure...

TM: un voluminoso expediente...

TO: La première de ces pièces était un procès-verbal dressé dans les termes suivants.

TM: El primer documento era un acta redactada en los siguientes términos. 
TO: commissaire de police, officier de police judiciaire, auxiliaire de monsieur le procureur impérial.

TM: comisario de policía, oficial de policía judicial, auxiliar del señor procurador imperial.

Podemos ver el uso constante a lo largo de la obra del vocablo "sieur", que se seguía utilizando en la época, en lugar de "monsieur" únicamente en el ámbito del lenguaje jurídico, así como, el vocablo "demoiselle", en lugar de "mademoiselle":

TO: Ladite demoiselle Andrée François nous donne comme suit le signalement du sieur François:

TM: La mencionada señorita Andrée François da, como sigue, la descripción del señor François:

TO: Au cours de cette opération, la demoiselle Andrée François nous remet trois lettres.

TM: En el curso de esta operación, la señorita Andrée François nos remite tres cartas.

Se encuentra el vocablo "jourd'hui", que como los anteriores dos casos nos transmiten el carácter vetusto de la obra, ya que son formas actualmente en desuso:

TO: «Ce jourd'hui 15 juin 1809, à la requête de M. le juge de paix...

TM: - En el día de hoy, 15 de junio de 1809, a requerimiento del señor juez de paz...

Utilizo el procedimiento traductológico de la amplificación, se complementa la traducción con estructuras verbales, adjetivas o nominales, la mayoría de las veces, añadiendo estructuras que no aparecen en TO, como en los siguientes casos:

TO: le plus grand ordre règne dans la pièce où nous nous trouvons.

TM: un gran orden general reina en la habitación donde nos encontramos.

En el siguiente caso, traduzco "velours d'Utrecht" directamente por "pana", porque, aunque el vocablo utilizado en francés implica una referencia histórica creo que en español no es habitual esta denominación y "extrañaría" al receptor:

TO: quatre fauteuils anciens recouverts en velours d'Utrecht. 
TM: cuatro sillones antiguos tapizados de pana.

Por otra parte, se observa también el procedimiento traductológico de la omisión, la eliminación de partes de la frase, innecesarias o excesivas en detalles redundantes.

TO: se leva tout à coup et répondit avec des sanglots dans la voix.

TM: se levantó de golpe y respondió entre sollozos.

TO: D.-Aviez-vous des relations de voisinage avec votre colocataire?

TM: P. — ¿Tenía usted relaciones de vecindad con él?

TO: II travaillait alors comme ouvrier tourneur...

TM: Por aquel entonces trabajaba de tornero...

TO: ses yeux, brillant d'un éclat fiévreux, se voilèrent alors de larmes abondantes.

TM: sus ojos, que brillaban con un fulgor febril, se velaron por las lágrimas.

Hay alteraciones y cambios de unos vocablos por otros, sustituciones de unos lexemas verbales por otros más adecuados que contribuyen a mantener la fluidez en lengua meta:

TO: Au premier se trouvait la dame Masouillet.

TM: En el primero vivía la señora Masouillet.

TO: - Je ne saurais préciser les dates...

TM: - No sabría decirle exactamente...

TO: L'une et l'autre s'emparèrent des mains de la jeune fille.

TM: Las dos cogieron las manos a la joven. contexto:

Sustituciones de sintagmas nominales por otros más adecuados al

TO: L'enfance inspire à ces derniers tristesse et regrets

TM: Los niños inspiran a estos últimos tristeza y nostalgia

En el caso de las unidades de medida, en que el texto francés utiliza "pas", habitual en francés, sin embargo en LM he optado por traducir por "metros", pues resultaría extraño expresar en español una distancia en "pasos": 
TO: à quelques centaines de pas de la place Dauphine.

TM: a unos metros de la plaza Dauphine.

TO: Or, à quelques pas de là, non loin du boulevard...

TM: Ahora bien, a pocos metros de allí, no lejos del bulevar...

Sustituciones de unos vocablos por otros, como en los siguientes ejemplos, donde además se sustituyen sintagmas nominales por sintagmas verbales:

TO: Andrée raconta dans ses moindres détails l'emploi de sa journée. TM: Andrée les contó con pormenores lo que había hecho ese día.

TO: le lit est préparé pour la nuit, la couverture en est défaite. TM: la cama está preparada para acostarse, el embozo está deshecho.

TO: -Ainsi, vous avez remis ces lettres à M. François lui-même? TM: - ¿Entonces, le dio las cartas al señor François en persona?

TO: Cette infirmité lui interdisait toute espèce de travail à l'extérieur. TM: Esta enfermedad le impedía realizar cualquier trabajo fuera de casa.

TO: Afin de pouvoir subvenir à ses besoins et atténuer l'horreur de sa situation

TM: Con el fin de poder subvenir a sus necesidades y aliviar su penosa situación.

Es de señalar el uso de la preposición "en" para especificar la materia de la que están hechos los objetos en francés, mientras en español utilizamos la preposición "de":

TO: nous apercevons une montre et une chaîne en or.

TM: vemos un reloj y una cadena de oro.

TO: ces couronnes en perles qu'on vend à la porte des cimetières.

TM: esas coronas de perlas que se venden en la puerta de los cementerios.

TO: quatre fauteuils anciens recouverts en velours d'Utrecht de couleur verdâtre, d'un guéridon en acajou, deux flambeaux en métal blanc et une pendule en cuivre doré, une petite table-bureau en noyer, une horloge avec caisse en bois. 
TM: cuatro sillones antiguos tapizados de pana de color verdoso, un velador de caoba, dos candelabros de metal blanco y un reloj de cobre dorado, una mesita-escritorio de nogal un reloj con caja de madera.

Encontramos expresiones figuradas o "expresiones hechas" en francés que traducimos por sus equivalentes en sentido en español, como en los siguientes casos:

TO: Ce que je sais, c'est que c'est un maniaque, un original, vivant un peu comme un loup.

TM: Lo que sé, es que es un maniático, un tío raro, que vivía casi como un ermitaño.

TO: Mon père, mon père, criait à mi-voix la pauvre enfant.

TM: Mi padre, mi padre, gritaba con voz apagada la pobre niña.

TO: Pour la dixième fois déjà, elle cherchait à pénétrer le mystère de ces diverses circonstances.

TM: Por enésima vez ya, buscaba averiguar el misterio de las distintas circunstancias.

TO: Cette phrase inachevée était profondément gravée dans sa mémoire.

TM: Esta frase inacabada estaba grabada a fuego en su memoria.

TO: Ce que je suis, ce que je sais, c'est à lui que je le dois; je suis son œuvre, le sang de sa chair.

TM: Lo que soy, lo que sé, se lo debo a él; yo soy su obra, sangre de su sangre.

TO: et je vous remercie $d u$ fond du cœur.

TM: y le agradezco de todo corazón.

TO: mais j'ai un pressentiment funeste.

TM: pero tengo un mal presentimiento.

Asimismo, se hallan frecuentemente expresiones de argot pertenecientes al francés popular, y se traslada a veces la pronunciación del lenguaje familiar, efecto que hemos buscado mantener en TM:

TO: - M'sieu François a fait sa pelotte.

TM: — El s'ñor François ha juntado un dineral.

TO: son entrée était saluée par les cris de: « V'là M'sieu François! I

V'là M'sieu François!» 
TM: su entrada era saludada par voces diciendo: « ¡El s'ñor François! ¡El s'ñor François!»

TO: il vivait avec une économie qui, dans le quartier, l'avait fait traiter de grigou.

TM: vivía con una economía que, en el barrio, lo tachaban de rácano.

TO: mais nous voudrions bien savoir comment il a fait pour gagner tout son quibus.

TM: pero ya nos gustaría saber cómo ha hecho para ganar todo el parné.

TO: avait une maîtresse qui devait lui manger tout l'argent qu'il amassait à force d'économie.

TM: tenía una amante que iba a pillarle todo el dinero que él amasaba a base de economía.

Es de destacar el uso del vocablo "père" para designar de manera familiar y afectuosa a los mayores, del modo en que aparece en Le père Goriot de Balzac, en español optamos por traducirlo por tío:

TO: je ne connais que très peu le père François, comme on l'appelle dans le quartier.

TM: conozco muy poco al tío François, como lo llaman en el barrio.

En el siguiente caso se opta por traducir la expresión "passer pour" por "aparentar", por parecer más familiar en español, además omitimos la expresión "aux yeux desquels" y simplificamos por "ante ellos":

TO: aux yeux desquels il passait pour un brave ouvrier.

TM: ante ellos aparentaba ser un honrado obrero.

En el siguiente ejemplo se menciona la actividad de venta de boletos de lotería haciendo referencia a "Camelot" que era el operador de la lotería nacional de Reino unido, lo hemos sustituido por "lotero", pues "camelot" es un término que no tiene ningún referente cultural en la lengua del receptor:

TO: Tantôt ouvrier, tantôt employé, tantôt «camelot».

TM: Ya obrero, ya empleado, ya lotero.

Por otra parte, merece una consideración especial el uso del vocablo Céladon en la expresión "vieux Céladon". El nombre se debe a un pastor, 
Celadón, personaje de la novela de $1610, L^{\prime}$ Astrée de Honoré d'Urfé ${ }^{7}$, que llevaba cintas verde pálido y debido a esto se dio nombre al color como "celadón"; sin embargo, he optado por perder la referencia histórica del vocablo y traducir simplemente por "viejo verde" ("vert galant"), pues creo que no es significativa para el receptor en LM:

TO: M. François fût alors traité de libertin, de vieux Céladon.

TM: El señor François fue tachado de libertino, de viejo verde.

Dentro de este plano léxico, es de señalar la dificultad en la traducción de términos referentes a la organización administrativa del territorio, ya que se estructura de forma diferente en LO y en LM, en este caso, ya que se trata de un texto literario y no administrativo, optamos por acercar la traducción al lector a expensas de perder propiedad en la denominación, ya que deberíamos traducir "arrondissement" por "distrito" y sin embargo optamos por el vocablo "comarca":

TO: le timbre du bureau de poste de Mézidon, chef-lieu de canton de l'arrondissement de Lisieux.

TM: el sello de la oficina de correos de Mézidon, cabeza de partido de la comarca de Lisieux.

\section{NOMBRES PROPIOS}

Dada su especial relevancia dedicamos un apartado especial a los nombres propios (NP) y, dentro de ellos, distinguiremos por un lado los antropónimos, y por otro los topónimos y nombres de instituciones.

\section{ANTROPÓNIMOS}

En el TM, en todos los casos de nombres propios, se han mantenido los nombres de los personajes, utilizando el procedimiento de la repetición, es decir, la reproducción exacta de la grafía de los NP originales. Es el método más conservador que existe y el más utilizado actualmente (Aixelá, 2000):

\footnotetext{
${ }^{7}$ La novela, considerada la primera novela-río de la literatura francesa ( 5 partes, 40 historias, 60 libros, 5.399 páginas), tuvo el enorme éxito en toda Europa (traducida a numerosos idiomas y leído en todas las cortes europeas). Fue escrita en una época en la que los productos "qingci» de los talleres chinos de Longquan tenían gran popularidad en Francia: el color de la porcelana china se comparó con la ropa de Celadón y esta asociación se ha mantenido incluso en otros idiomas. En la Real Academia Española, no existe la palabra "celadón", pero sí la que hace acepción al color verdeceladón o verdeceledón. El Diccionario de María Moliner, por otro lado sí que recoge tanto "celadón" como "celedón".
} 
TO: Ladite demoiselle Andrée François...

TM: La mencionada señorita Andrée François...

TO: mon élève, mademoiselle Camille de Meyrins.

TM: mi alumna, la señorita Camille de Meyrins.

TO: «Je me nomme Virginie-Marie Son, veuve Masouillet.

TM: Me llamo Virginie-Marie Son, viuda de Masouillet.

TO: «Le sieur Mérignac, Antoine, ouvrier maçon.

TM: -El señor Mérignac, Antoine, peón albañíl.

\section{TOPÓNIMOS Y NOMBRES DE INSTITUCIONES}

Los lugares, de los que Bizouard da informaciones muy precisas, existen en la realidad, se encuentran en París, nos traslada a los viejos barrios y sus inmediaciones, donde se publica y se lee la novela y son, sin duda, conocidos por los lectores en LO.

Los procedimientos traductológicos pueden ser muy variados. En la mayoría de los casos opto por el procedimiento de la repetición tanto para los nombres propios instituciones como para los nombres propios de lugares, es decir, se trasladan al TM sin traducirse:

TO: née à Gray (Haute-Saône).

TM: nacida en Gray (Haute-Saône).

TO: L'île de la Cité offre à ce point de vue un exemple frappant...

TM: La île de la Cité ofrece a este respecto un ejemplo impresionante...

TO: qu'on appelle le boulevard Saint-Michel.

TM: llamado el bulevar de Saint-Michel.

En las ocasiones en que hay un equivalente conocido en LM, doy el nombre correspondiente en español:

TO: Le Palais de Justice, le Tribunal de Commerce, la Morgue et la Préfecture de police ne résument-ils pas, en effet, notre civilisation? TM: ¿El Palacio de Justicia, el Tribunal de Comercio, la Morgue et la Prefectura de Policía no resumen, en efecto, nuestra civilización?

TO: «Je suis arrivée hier, lundi, 13 juin, à Paris, venant de Normandie...

TM: -Llegué ayer, lunes, 13 de junio, a París, procedente de Normandía... 
TO: les deux immenses tronçons de la ville séparés par la Seine.

TM: las dos inmensas partes de la ciudad separadas por el Sena.

TO: il allait faire chaque matin une promenade dans le jardin $d u$ Luxembourg...

TM: iba a dar un paseo cada mañana por el jardín de Luxemburgo...

TO: à quelques pas de là, non loin du boulevard du Palais...

TM: a pocos metros de allí, no lejos del bulevar del Palacio de Justicia...

En este último ejemplo se utiliza el procedimiento intratextual de la amplificación, para añadir información dentro del texto, con objeto de hacer más completa la información sin necesidad de poner una Nota del Traductor.

Es significativo el caso del vocablo "sûreté", que en numerosas traducciones hemos visto traducido literalmente por "seguridad", utilizando el procedimiento traductológico del calco. Se opta por mantener el nombre del organismo tal cual, pues al traducirlo se pierde la singularidad del término, tan característico y propio para designar a la institución policial francesa; en este caso, además, se pone el nombre en mayúscula haciendo referencia al propio organismo:

TO: avait mis les agents du service de sûreté en campagne.

TM: había movilizado a los agentes de la Sûreté.

\subsection{Plano pragmático-cultural}

En la obra domina el ambiente judicial, haciéndose referencias continuas a documentos, cargos y empleados del ministerio judicial, al funcionamiento y a la situación de la justicia, ya desde el propio inicio del relato:

Le 10 juin 1869, la Préfecture de police de Paris recevait dans la matinée une volumineuse procédure relative à un fait assez étrange La première de ces pièces était un procès-verbal dressé dans les termes suivants:

Devant nous, Duplex (Auguste), commissaire de police de la ville de Paris, plus spécialement chargé du quartier Notre-Dame, officier de police judiciaire, auxiliaire de monsieur le procureur impérial,

Se présente la demoiselle Andrée François, âgée de 18 ans, institutrice, demeurant chez madame de Meyrins, rue de Verneuil 18, Qui nous déclare ce qui suit: (...)

Ladite demoiselle nous dépose une photographie de son père, que nous transmettons ci-joint.

Lecture faite, la demoiselle François a persisté et signé avec nous. 
Le commissaire de police,

Signé: ANDRÉE FRANÇOIS

Signé: DUPLEX

\section{Conclusions}

De tout quoi, nous avons dressé le présent procès-verbal qui sera transmis en la forme ordinaire à $\mathrm{M}$. le préfet de police aux fins de droit.

DUPLEX

Encontramos numerosos comentarios sobre la sociedad parisina y sobre la propia ciudad, con su aspecto cosmopolita frente a otras zonas más deprimidas:

TO: Ce coin de Paris où s'agitent tant d'intérêts divers...

TM: Este rincón de París donde se mueven tantos y tan diversos intereses...

TO: non loin du boulevard du Palais et du boulevard si gai, si vivant qu'on appelle le boulevard Saint-Michel, sur la gauche de l'église Notre-Dame se trouve une rue qui semble appartenir à une ville morte. TM: no lejos del bulevar del Palacio de Justicia y del bulevar tan alegre, tan vivo llamado el bulevar de Saint-Michel, a la derecha de la iglesia Notre-Dame hay una calle que parece pertenecer a una ciudad muerta.

TO: Le sol, les murs, les maisons, tout y indique l'abandon et inspire la crainte et l'effroi.

TM: El suelo, las paredes, las casas, todo muestra abandono e inspira miedo y pavor. francesa:

Sobre la organización y el funcionamiento de la institución policial

TO: officier de police judiciaire, auxiliaire de monsieur le procureur impérial

TM: oficial de policía judicial, auxiliar del señor procurador imperial

TO: les incidents mystérieux, que l'enquête ouverte par le commissaire de police avait relevés.

TM: los misteriosos incidentes, que la investigación abierta por el comisario de policía había destapado

TO: Les prisons, les asiles d'aliénés, les hôpitaux, la Morgue avaient été fouillés sans résultat

TM: Las prisiones, los manicomios, los hospitales, la Morgue habían sido escudriñados sin resultado 
Otro aspecto importante a destacar es la información que aporta con la descripción de la vestimenta y el aspecto propios de la época:

TO: Il porte des favoris qui, comme ses cheveux, sont blancs.

TM: Lleva patillas que, como su pelo, son blancas.

TO: Il devait être vêtu, lorsqu'il a disparu, d'une grande redingote à taille, en drap de couleur marron, d'un gilet en alpaga noir et d'un pantalon gris.

TM: -Debía llevar, cuando desapareció, una gran levita a la medida, en tela de color marrón, un chaleco de alpaca negro y un pantalón gris.

TO: ses yeux bleus, ombragés de sourcils touffus, étaient d'une douceur infinie.

TM: sus ojos azules, cercados de espesas cejas, eran de extremada dulzura.

Así como la descripción del mobiliario y el aspecto de las viviendas:

TO: quatre fauteuils anciens recouverts en velours d'Utrecht de couleur verdâtre, d'un guéridon en acajou avec pieds ornés de grosses têtes de sphynx; sur la cheminée se trouvent deux flambeaux on métal blanc et une pendule d'albâtre à colonnes, dont le balancier représente un soleil, en cuivre doré... une horloge avec caisse en bois, dite coucou.

TM: cuatro sillones antiguos tapizados de pana de color verdoso, un velador de caoba cuyas patas están decoradas con grandes cabezas de esfinges; en la chimenea hay dos candelabros de metal blanco y un reloj de alabastro con columnas, cuyo péndulo representa un sol, de cobre dorado... un reloj con caja de madera, un cucú.

Las referencias a la historia a la cultura occidental son constantes a lo largo del relato:

TO: saisir la corde noire et graisseuse qui sert de fil d'Ariane dans ce labyrinthe aux marches usées.

TM: agarrar la cuerda negra y grasienta que sirve de hilo de Ariadna en ese laberinto de escalones desgastados.

TO: cet individu semblait être le véritable Protée du travail.

TM: ese individuo parecía ser el verdadero Proteo del trabajo.

TO: l'expression de tristesse de sa physionomie ne saurait être rendue que par le pinceau des Wilhem, des Calix Comte, des Heilbuth... 
TM: la expresión de tristeza de su fisonomía solo habría podido transmitirla el pincel de un Wilhem, un Calix Comte, un Heilbuth...

En el siguiente ejemplo se hace referencia a uno de los personajes principales de Le Juif errant, novela de Eugène Sue que gozó de un extraordinario éxito en la época y que fue publicada en forma de folletín en Le Constitutionnel ${ }^{\beta}$, apareciendo en forma de volumen de 1844 a 1845:

TO: il faisait lui-même son ménage, lavait sou linge, comme le sympathique Dagobert du Juif errant

TM: se arreglaba él mismo la casa, lavaba la ropa, como el bueno de Dagoberto del Judío errante

La descripción de los comportamientos sociales, las referencias a las diferencias entre clases sociales, a las viviendas, a los hábitos y a la forma de ganarse el sustento de las clases más desfavorecidas, hacen de esta novela un verdadero tesoro para el estudio del París de la época:

TO: II changeait fréquemment de profession, vivant des mille ressources qu'offre la petite industrie parisienne.

TM: Cambiaba con frecuencia de profesión, viviendo de los miles de recursos que ofrece la pequeña industria parisina.

TO: un ouvrier qui vit de rentes acquises par son travail est un fait trop rare pour ne pas éveiller l'attention.

TM: un obrero que vive de las rentas obtenidas por su trabajo es algo demasiado raro para no llamar la atención.

TO: Afin de pouvoir subvenir à ses besoins et atténuer l'horreur de sa situation...

TM: Con el fin de poder subvenir a sus necesidades y aliviar su penosa situación...

TO: se trouvait seule au monde et presque dans le dénuement.

TM: se encontraba sola en el mundo y casi en la miseria.

TO: la dame Masouillet, pauvre femme, veuve d'un petit employé de l'Etat qui, en mourant, ne lui avait laissé pour toutes ressources qu'une maigre pension de cinq cents francs.

\footnotetext{
${ }^{8}$ El libro fue uno de los mayores éxitos del siglo XIX. Publicado del 25 de junio de 1844 al 26 de agosto de 1845 en Le Constitutionnel, con esta novela (de 800 páginas), el número de abonados del periódico pasó de 3600 à 23600 .
} 
TM: la señora Masouillet, una pobre mujer, viuda de un empleadillo del estado que, al morir, le había dejado como únicos recursos una flaca pensión de quinientos francos.

\section{CONCLUSIÓN}

Como se evidencia por los numerosos casos que han ido ejemplificando los necesarios cambios del texto origen al texto meta, la elevada frecuencia de alteraciones en las estructuras sintácticas de las frases, las sustituciones de unas estructuras léxicas por otras, las omisiones, las amplificaciones, las obligadas transposiciones de expresiones figuradas por sus equivalentes de sentido, aunque distantes en estructura y léxico, en lengua meta,... en fin, la ingente necesidad de modificaciones de todo tipo, hace patente que la traducción de textos literarios es un fenómeno de "reescritura", en el que la función del traductor es de una importancia capital, ya que en el proceso de traducción intervienen múltiples factores, tanto textuales y extra textuales en la lengua origen, como textuales y extra textuales en la lengua meta.

A este respecto, la labor traductológica adquiere una gran importancia ya que el traductor debe tener un gran conocimiento de la lengua y la cultura de la que traduce, así como de la lengua y la cultura de llegada, pues son muchos los factores que debe discernir y comprender en lengua origen para poder transformarlos y adaptarlos a la lengua de destino.

Los factores extra textuales, el contexto histórico, los factores sociales y la intencionalidad del autor son determinantes en una obra y la labor del traductor es mantenerlos y buscar los mismos objetivos del autor en una lengua y una cultura de llegada diferentes, por lo que a veces hay que sacrificar traducir la palabra para poder trasladar el espíritu de la obra, como en el caso de esta traducción, donde se busca mantener el carácter de encuesta judicial, con un vocabulario y unas estructuras sintácticas propias del lenguaje administrativo y jurídico, con unas descripciones de las diferentes clases sociales en las que se muestra de forma inequívoca la empatía del autor con las clases más desfavorecidas y la crítica social a la alta burguesía parisina de la época.

Así pues, la función del traductor de obras literarias es también la de "mediador" entre culturas ya que traslada el texto manteniendo la función estética, el estilo, los contenidos y los objetivos buscados por el autor en lengua origen para un lector de una cultura y una lengua diferentes.

REFERENCIAS BIBLIOGRÁFICAS

AIXELÁ, Javier Franco, La traducción condicionada de los nombres propios. Salamanca: Editorial Almar, 2000. 
Bellet, Roger, Presse et journalisme sous le Second Empire. Paris: Armand Colin, 1967.

BenvenutI, Stefano; Lebrun, Michel; RizzonI, Gianni, Le Roman criminel, histoire, auteurs, personnages. Nantes: L'Atalante, 1982.

CARADEC, François, Dictionnaire du français argotique et populaire. Paris: Larousse, 1988.

CORPAS PASTOR, Gloria, Manual de fraseología española. Madrid: Gredos, 1997.

Diebolt, Évelyne, Le Petit Journal et ses romans-feuilleton 1863-1914, "Thèse de $3^{\mathrm{e}}$ cycle". Université de Paris VII, 1975.

GeORLETTE, René, Le Roman-Feuilleton français. Bruxelles: Chez l'auteur, 1955.

HURTADO AlBIR, Amparo, Traducción y traductología. Introducción a la traductología. Madrid: Ediciones Cátedra, 2001.

Nord, Christiane, Texto base-texto meta: un modelo funcional de análisis pretraslativo. Castellón de la Plana: Publicacions de la Universitat Jaume I, 2012.

Olivier-Martin, Yves, Histoire du roman populaire en France: de 1840 à 1980. Paris: Albin Michel, 1980.

QUEFFELEC, Lise, Le Roman feuilleton au XIXe siècle. Paris: P.U.F., 1989. 